\title{
Correction to: Therapeutic Efects of Boric Acid in a Septic Arthritis Model Induced by Escherichia coli in Rats
}

\author{
Kadri Yıldız ${ }^{1}$ Mustafa Makav ${ }^{2} \cdot$ Yasemen Adalı $^{3} \cdot$ Menekşe Bulut $^{4}$
}

Published online: 7 February 2022

○) Springer Science+Business Media, LLC, part of Springer Nature 2022

\section{Correction to: Biological Trace Element Research} https://doi.org/10.1007/s12011-021-03065-7

The original version of this article unfortunately contained a mistake. The name of Yasemen Adalı is now corrected in the author group.

The original article has been corrected.

Publisher's Note Springer Nature remains neutral with regard to jurisdictional claims in published maps and institutional affiliations.

The original article can be found online at https://doi.org/10.1007/ s12011-021-03065-7.

Kadri Y1ldiz

drkadri1980@hotmail.com

1 Orthopeadia and Traumatology Department, Kafkas University Medical School, Ana Kampüs, 36000 Kars, Turkey

2 Physiology Department, Kafkas University Veterinary School, Kars, Turkey

3 Department of Pathology, Faculty of Medicine, Izmir University of Economics, İzmir, Turkey

4 Food Engineering Department, Faculty of Engineering, Igdır University, Igdır, Turkey 